\title{
Experimental Research and Method for Calculation of 'Upsetting-with-Buckling' Load at the Impression-Free (Dieless) Preforming of Workpiece
}

\author{
Volodymir Kukhar ${ }^{1}$, Victor Artiukh ${ }^{2 *}$, Andrii Prysiazhnyi $^{1}$ and Andrey Pustovgar $^{3}$ \\ ${ }^{1}$ Pryazovskyi State Technical University, Universytetskaya str., 7, Mariupol, 87500, Ukraine, \\ ${ }^{2}$ Peter the Great St. Petersburg Polytechnic University, Polytechnicheskaya str., 29, 195251, Saint- \\ Petersburg, Russia, \\ ${ }^{3}$ Moscow State University of Civil Engineering, Yaroslavskoe shosse, 26, Moscow, 129337, Russia
}

\begin{abstract}
This paper presents the results of experimental studies of load characteristic changes during the upsetting of high billets with the upsetting ratio (height to diameter ratio) from 3.0 to 6.0 , which is followed by buckling. Such pass is an effective way of preforming the workpiece for production of forgings with a bended axis or dual forming, and belongs to impression-free (dieless) operation of bulk forming. Based on the experimental data analysis, an engineering method for calculation of workpiece pre-forming load as a maximum buckling force has been developed. The analysis of the obtained data confirmed the possibility of performing of this pre-forming operation on the main forging equipment, since the load of shaping by buckling does not exceed the load of the dieforging.
\end{abstract}

\section{Introduction}

Upsetting and bending are the most common operations in press-forging industry. Upsetting is mostly performed as a pressing between two flat dies, although the dies should still be regarded as a pressing deforming tool that has contoured working faces or impressions which provide the necessary shape to the product after pressing. Upsetting by uncontoured dies is more common. Its purpose is descaling, increasing of workpiece diameter for subsequent cogging, swaging, impression forging or die-forging of forgings with a round in plan view area cross section, improving the inner metal structure and growth of new fine grains [1]. Bending is used for bulk and sheet metal forming, and this operation is usually carried out using contoured dies, forming rolls or bending machines [1-3].

\footnotetext{
*Corresponding author: artiukh@mail.ru
} 
We propose and investigate a brand new bulk forming process, such as preforming of workpiece for subsequent open die or closed die forging by upsetting of billet with large ratio of height to diameter (upsetting ratio more then 3.5), followed by buckling. Bulk forming of workpiece by upsetting with buckling is performed as a single-stroke process and one such operation combines at least three: descaling, bending and redistribution of metal along the length of a workpiece (edging, fullering or gathering - as at drop-forging). Given that it is a question of hot-forming processes, this forming operation is performed after heating the workpiece in a furnace. Buckling, accompanied by the edging and fullering of metal along the bended axis, should be attributed to one of the most effective methods of bulk dieless preforming, which has not been sufficiently studied to the present time. The practice of such operation for forming of forgings with a bended axis or dual forming [4] showed fine results in saving of metal (at least 20\%), however, the load behaviour during the working stroke of 'upsetting-with-buckling' of workpieces with different upsetting ratio remain unstudied. The study of load behaviour as force modes is relevant for the right choice of appropriate production equipment, standardized gaps in the press and dies guides, angular deflection of frames and the development of combined die forging processes with the preforming and final forming of the metal product in a single die holder (sub-sow block) in automatic forging modes.

\section{Review}

In practice, the upsetting of workpieces with the ratio of the initial height $L_{0}$ to the diameter $D_{0}$ (upsetting ratio) $m_{0}=L_{0} / D_{0}>3.5$ is not used to exclude buckling, which is considered a negative phenomenon. However, different researchers determined a different critical value of the upsetting ratio $m_{0}=L_{0} / D_{0}$ between 2.7 and 4.3, at which the buckling of a high cylindrical workpieces occurs, which depends on the conditions at the ends of the workpiece, material type, process temperature, etc. The upper value of the possible height of the workpiece is limited by the dimensions of press frame gap. There are a lot of studies in the field of buckling of various systems, but they do not concern the practical application of the technology of bulk forming.

The strain of thin-walled shells, columns and rods has a sufficient number of modern fundamental studies [5-7], which can not be used to predict the shape changes and the behaviour of the load modes of plastic billets, which buckled during upsetting due to the discrepancy between geometric and boundary conditions. Processes which cause buckling are negative for the formation of thin-walled sheet and tubular products by the methods of sheet-metal forming, which was researched in [8] by finite element modelling and tested experimentally. It is shown that in order to predict the buckling nature, it is necessary to take into account the properties of the material and the geometric parameters of the workpiece. In addition, it is very important to exclude inaccuracies of the "press-die" system to provide quality of formed products from a sheet blanks [9]. In the paper [10], bending of thin-walled cylindrical shells that contain one welding seam was studied. The graphs of the ration of load force and bending deflection have been experimentally constructed. A comparison is made with theoretical assumptions based on Koiter's approach, relating to asymmetrically applied critical loads. The results are applicable only to the elastic region and it is impossible to estimate the variation of the load behaviour of the rods and shells experiencing plasticity buckling.

The buckling of aircraft panels under static loads to track the appearance of fatigue cracks was studied in the work [11]. Moreover, in order to increase the static load, it is proposed to introduce protective properties of the skin of the panels. Obviously, buckling strain is seen as a negative process, leading to a decrease in the durability of such panels. The results of studies [12] show that the use of workpieces with a profiled lateral surface allows 
to increase the value of the critical load by $20 \ldots 40 \%$ in comparison with not preformed workpieces. An important factor is the shape factor, namely the effect of "side-to-thickness ratio" and for functionally structured materials for support plates production, to which specific requirements are imposed [13].

There are studies in the field of thermal buckling of silicone ribbon [14], which are produced with different pull speeds from the furnace. Among the main factors affecting the buckling behaviour, a geometric factor is also identified, i.e. shape of the ribbon profile. Positive use of the phenomenon of buckling is observed by the researchers in the simulation and experiments on the production of two-rib plates [15]. However, this effect relates to a horizontally placed workpiece in the closed die with the application of punch power load to the middle of workpiece. The flow of metal to the opposite sides leads to buckling with the tides of the metal and the beginning of the formation of two ribs on the sides of the punch.

In work [16] it was suggested to consider the preforming of workpieces by upsetting with buckling as one of the options for dieless shaping of workpieces for subsequent open die or closed die forging. Thermal preforming (thermal intensification with a given gradient of heating) of workpieces [17], and stretching with a rupture of workpieces, carried out with the localization of the heated part [18], are referred to a dieless impression-free forging technologies. Modern technologies of incremental forming without dies are carried out with a pencil-like tool with local and sequential forming of the profile on the sheet blank using CNC machines $[19,20]$. Such processes, developed in Japan and spread to European countries, do not belong to bulk preforming and are carried out in a cold condition, allowing to form a sheet products in just a few minutes with utmost precision. The thermal localization of deformation allows the development of processes of dieless drawing of wires [21] and tubes $[22,23]$ of stainless steels and non-ferrous metals. The control of the shape-change happens due to the creation of a thermal field by a moving inductor when the required speed-related deformation modes are realized, eliminating unregulated distortions and rupture of a workpiece. This is dominated by the processes of stretching, not compression and bending, as in the case of a upsetting with buckling.

The studies on the longitudinal compression of beam beyond the elastic limit indicate an increase in the value of the load to the point of the local transition of the rod to the plastic state [24-26]. Further upsetting can be characterized by a general unloading due to an increase in the bending moment arm, which is associated, for example, with the difficulty of obtaining an increasing characteristic of ring fuses with longitudinal slots. Information about the load behaviour in the buckling of inflexible rods or beams (upsetted billets) that are completely in the plastic state with a continuous and uneven increase in the crosssectional area is absent, which causes the scientific novelty of the problem, which in the present paper was experimentally solved.

\section{The Purpose}

The purpose of the present research is the experimental study of the load behaviour (force modes) at the upsetting of workpieces with the upsetting ratio $\mathrm{m}_{0}=\mathrm{L}_{0} / \mathrm{D}_{0}=3,0 \ldots 6,0$ followed by bulk buckling and the development of an engineering method for calculating of the operation load to adapt to the conditions of die-forging on a particular type of equipment.

\section{Material of research}

The object of the study was the upsetting process of relatively high workpieces with upsetting ratio $\mathrm{m}_{0}=\mathrm{L}_{0} / \mathrm{D}_{0}=3.0 \ldots 6.0$ (interval 0.5 ) by flat parallel dies on the universal testing 
machine of R-20 model (ultimate load $200 \mathrm{kN}$, indication error for loads $\pm 1 \%$ of the measured value, starting from $10 \%$ of the scale limit value, but not below $4 \%$ of the maximum load of the machine).

The subject of the study is the load characteristics of the 'upsetting-with-buckling' process. The maximum load value (of the used scale "B") is $100 \mathrm{kN}$.

The recording of the current load was carried out continuously during the deformation by the built-in drum-type load-measuring device in the R-20 machine. Deformation tool are upsetting dies of steel $5 \mathrm{HNV}$ grade $(\mathrm{C}=0.5 \ldots 0.6 \%, \mathrm{Si}=0.1 \ldots 0.4 \%, \mathrm{Mn}=0.5 \ldots 0.8 \%$, $\mathrm{Ni}=1.4 \ldots 1.8 \%, \mathrm{~S}<0.03 \%, \mathrm{P}<0.03 \%, \mathrm{Cr}=0.5 \ldots 0.8 \%, \mathrm{~W}=0.4 \ldots 0.7 \%, \mathrm{Cu}<0.3 \%, \mathrm{Fe} \approx 95 \%)$, heat-treated up to HRC 40-44 with roughness of the supporting surface $R a=6.3 \mu \mathrm{m}$.

According to the Kirpichev \& Kik's basic theories of the similarity, laboratory workpieces (specimens) should be geometrically and physically similar to industrial workpieces. The workpieces with a diameter of $30 \mathrm{~mm}$ were made by pressing a rod made of leadantimony alloy with a draw ratio of 7.1, thereby destroying the original cast dendritic structure. To comply with the physical similarity conditions for low-alloy structural steels classes with the presence of a single maximum on the stress-strain curve, the use of specimens from lead or antimony alloyed lead is generally accepted [27].

This is due to the fact that the deformation of lead at a room temperature is accompanied by recrystallization, as a result of which lead and heated steel detect, at different temperatures, qualitatively close dependences of the flow-stress behaviour on the strain rate and degree of deformation.

By bringing the parameters with the same dimensions to the dimensionless form the geometric similarity was observed in the subsystem, which consists of the initially independent parameters - is the dimensions of the workpieces $\left(L_{0}\right.$ and $\left.D_{0}\right)$ and the upsetting stroke $X=\left(L_{0}-H_{K}\right)$, where $H_{K}$ is a final height of the upset-bended workpiece (that is the final distance between faces of flat upsetting dies).

The upsetting ratio $m_{0}=L_{0} / D_{0}$ and the conditional degree of deformation $\varepsilon_{y}=\left(X / L_{0}\right) \times 100 \%$ are the dimensionless arguments of the functions of load for a upsetting with buckling.

Workpieces (specimens) after 'upsetting-with-buckling' process are shown in Fig. 1.

The indication diagrams of the current loads $(P)$ obtained during upsetting with buckling (stroke $-X, \mathrm{~mm}$ ) of specimens with different upsetting ratio is shown in Fig. 2.

When recalculating to dimensionless coordinates, the conditional degree of deformation of the buckled workpiece was determined as

$$
\varepsilon_{y}=\frac{X}{L_{0}}(\times 100 \%) .
$$

The current specific load $(p)$ for the 'upsetting-with-buckling' process was obtained from the value of the current load:

$$
p=\frac{P}{\left(\frac{\pi D_{0}^{2}}{4}\right)} .
$$

The dependences $p\left(m_{0} ; \varepsilon_{y}\right)$ are illustrated in Fig. 3. 

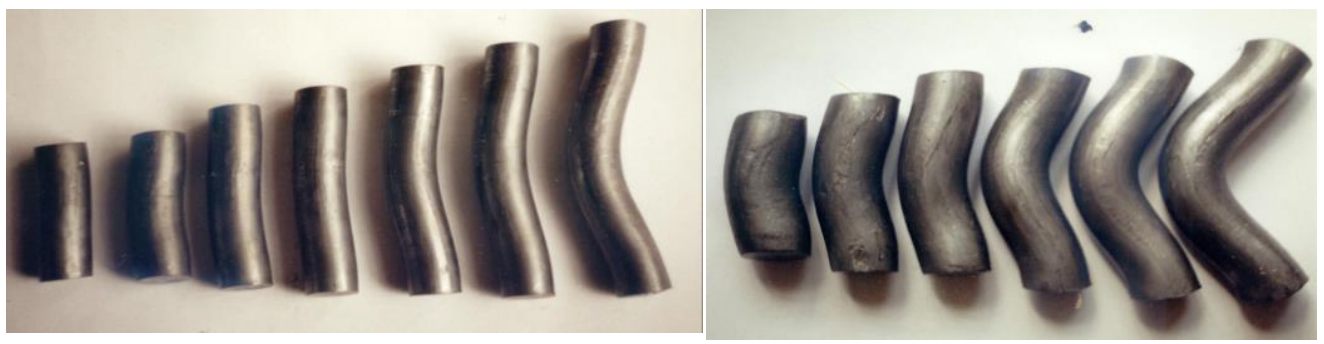

a

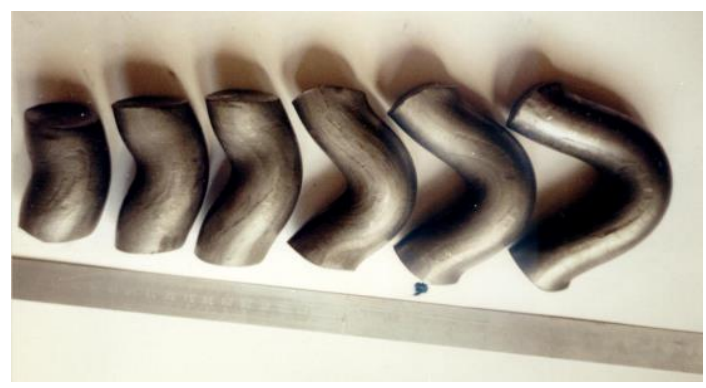

c $\mathrm{b}$

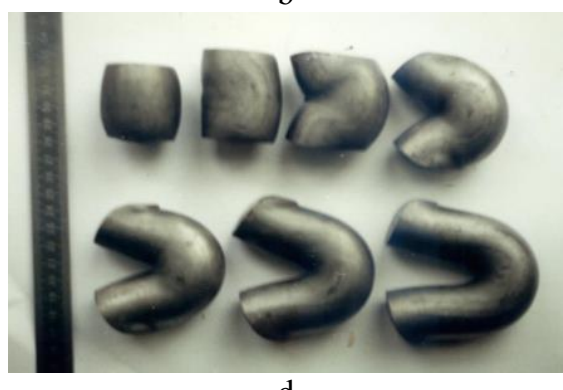

d

Fig. 1. Experimental workpieces with initial diameter $D_{0}=30 \mathrm{~mm}$ upsetted with buckling:

$$
\begin{aligned}
& \mathrm{a}-\varepsilon_{y}=13 \%, m_{0}=3.0 ; 3.5 ; 4.0 ; 4.5 ; 5.0 ; 5.5 ; 6.0 ; \\
& \mathrm{b}-\varepsilon_{y}=27 \%, m_{0}=3.5 ; 4.0 ; 4.5 ; 5.0 ; 5.5 ; 6.0 ; \\
& \mathrm{c}-\varepsilon_{y}=40 \%, m_{0}=3.5 ; 4.0 ; 4.5 ; 5.0 ; 5.5 ; 6.0 ; \\
& \mathrm{d}-\varepsilon_{y}=13 \%, m_{0}=3.0 ; 3.5 ; 4.0 ; 4.5 ; 5.0 ; 5.5 ; 6.0
\end{aligned}
$$

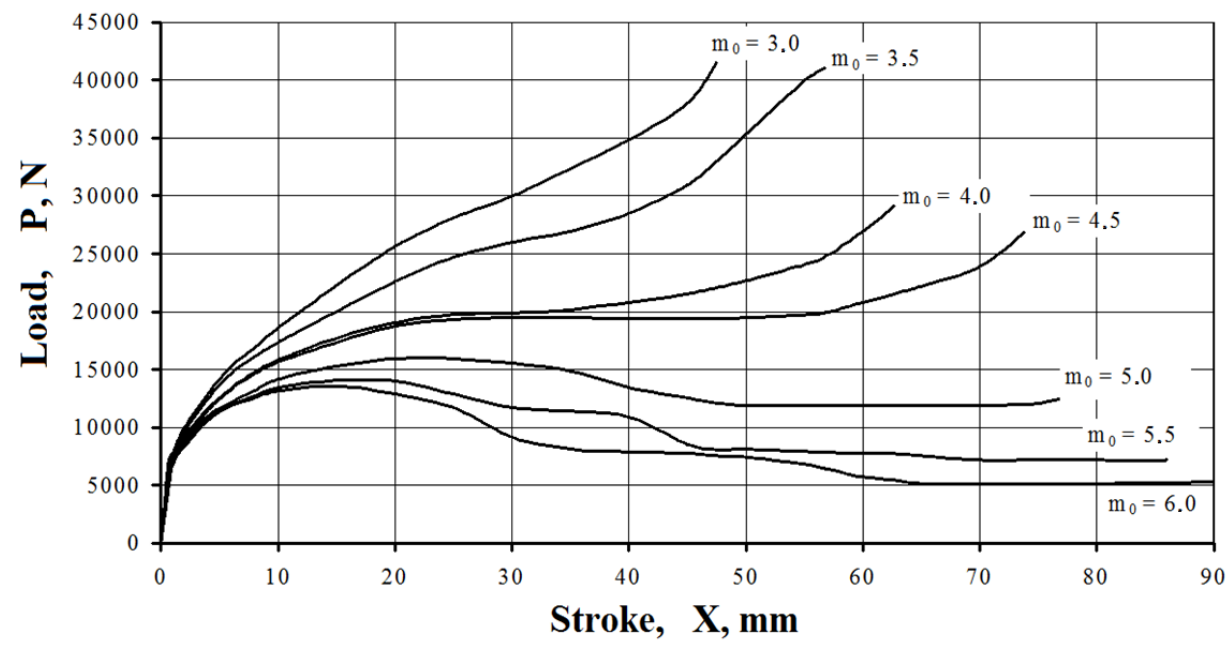

Fig. 2. Indicator diagram of the 'upsetting-with-buckling' process for antimony alloyed lead specimens 


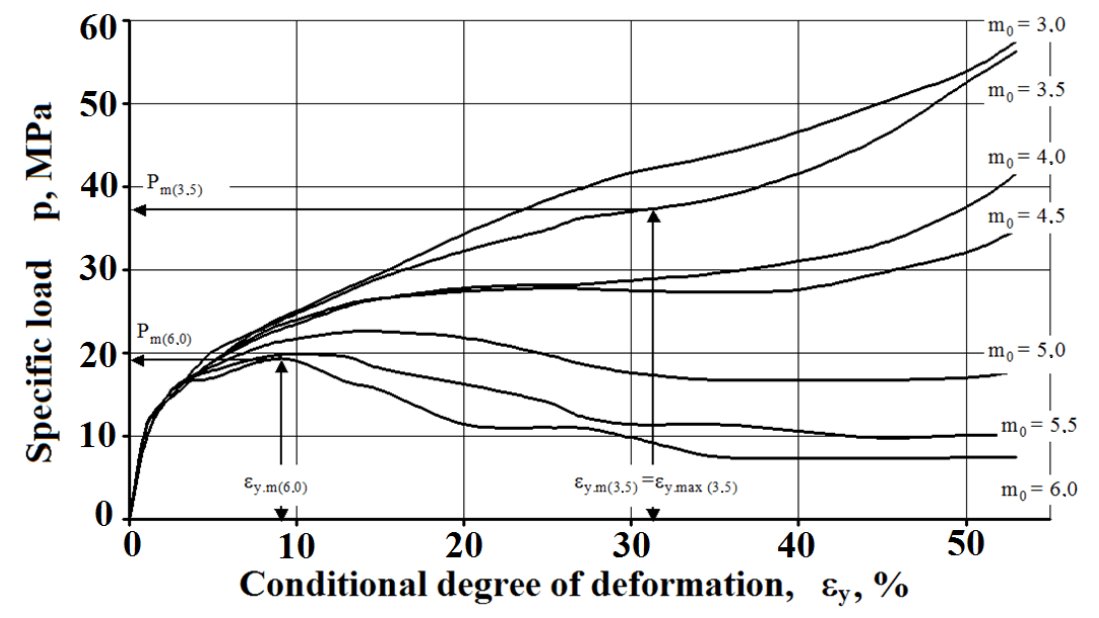

Fig. 3. Specific loads during upsetting by buckling of antimony alloyed lead specimens

The method of upsetting of cylindrical workpieces was used for obtaining a stress-strain curve $\sigma_{s}(\varepsilon)$, i.e. the dependence of the true flow stress $\left(\sigma_{s}\right)$ of the specimens material on the upsetting degree - compression strain $\varepsilon$. A series of workpieces with $m_{0}=L_{0} / D_{0}=1.1 \ldots 2.1$ ratio were upsetted; the deforming tool is flat parallel dies of $5 \mathrm{HNV}$ steel grade, the roughness of the surface is $R a=0.63 \mu \mathrm{m}$. The deformation strain rate was of $\dot{\varepsilon}=0.03 \ldots 0.07 \mathrm{~s}^{-1}$. The contact surfaces were lubricated with machine oil for approximate the stressed state to uniaxial compression.

The calculation of $\sigma_{s}$ was based on the data in Fig. 4 obtained by the equations [28]: a) S.I. Gubkin \& E. Siebel; b) A.F. Golovin; c) E.P. Unksov; d) K. Reisheter.

When getting the dependences of $\sigma_{s}(\varepsilon)$ for antimony alloyed lead (Fig. 5), it was found that the curves calculated according to the equations of Gubkin \& Siebel, Golovin, and Unksov coincide qualitatively and quantitatively (a difference of less than $0.5 \%$ ). The curve calculated according to the Reisheter equation is in full qualitative agreement with other graphs; however the values of $\sigma_{s}$ are overestimated, in comparison with the previous three ones, by an average of $14 \%$ (Fig. 5).

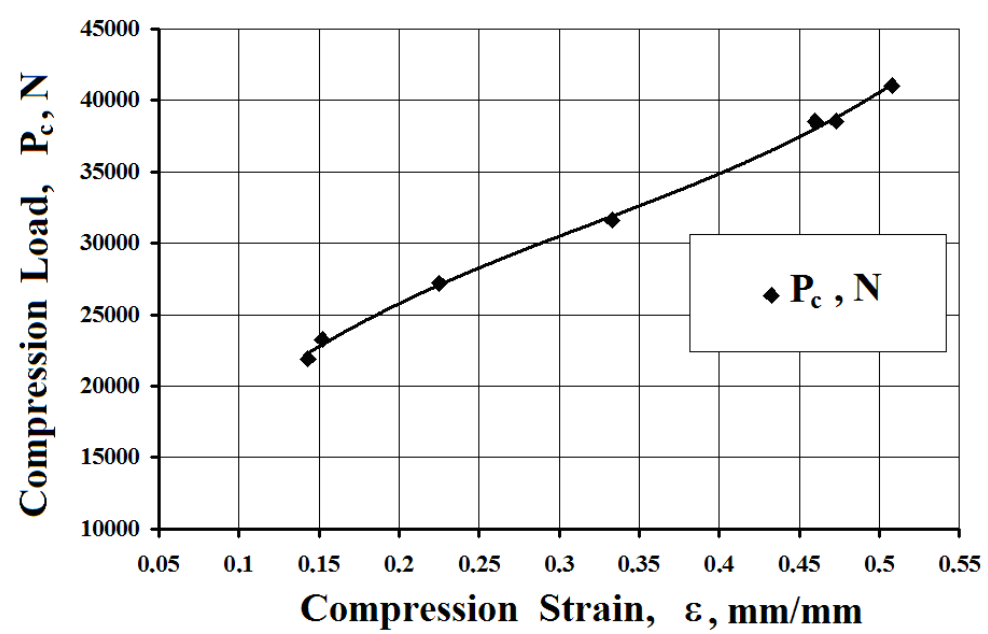

Fig. 4. Load by the method of cylindrical workpieces upsetting (antimony alloyed lead) 


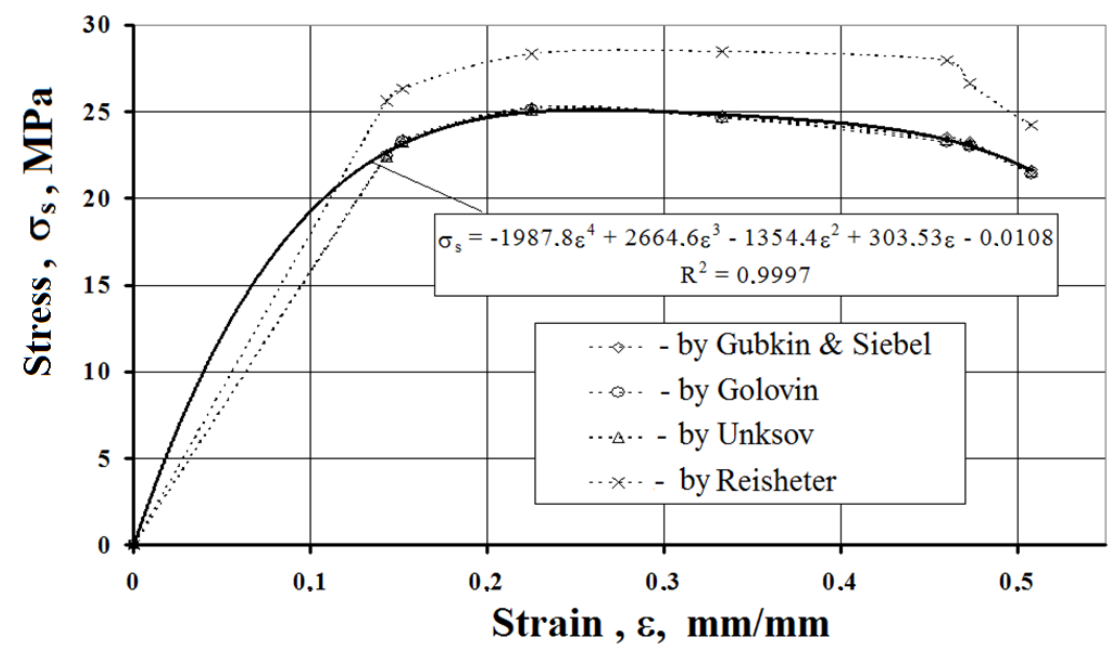

Fig. 5. The stress-strain curves $\sigma_{s}(\varepsilon)$ of specimens material (antimony alloyed lead) processed by different methods after the compression test

The obtained curve of the true values of the flow stress calculated by the above-mentioned Unksov's equation, were approximated (Fig. 5) with the accuracy of $\mathrm{R}^{2}=0.9997$ by the equation:

$$
\sigma_{s}=-1987.8 \cdot \varepsilon^{4}+2664.6 \cdot \varepsilon^{3}-1354.4 \cdot \varepsilon^{2}+303.53 \cdot \varepsilon-0.0108 .
$$

The strain of longitudinal compression at upsetting with buckling can be fully characterized by the shortening $(\delta$ ) of the axis:

$$
\delta=\frac{L_{0}-L_{K}}{L_{0}}(\times 100 \%)
$$

where $L_{K}$ - the final length along the bended axis of the workpiece.

The shortening function of the workpiece axis is interpolated by the equation:

$$
\delta \cdot 100 \%=\delta\left(\varepsilon_{y} ; m_{0}\right) \times 100 \%=A_{\delta} \cdot m_{0}^{3}+B_{\delta} \cdot m_{0}^{2}+C_{\delta} \cdot m_{0}+D_{\delta},
$$

where $A_{\delta}=-0.0031 \cdot \varepsilon_{y}^{2}+0.3105 \cdot \varepsilon_{y}-5.2317$;

$$
\begin{gathered}
B_{\delta}=0.0454 \cdot \varepsilon_{y}^{2}-4.4138 \cdot \varepsilon_{y}+72.376 \\
C_{\delta}=-0.212 \cdot \varepsilon_{y}^{2}+19.908 \cdot \varepsilon_{y}-321.28 \\
\quad D_{\delta}=0.3127 \cdot \varepsilon_{y}^{2}-27.574 \cdot \varepsilon_{y}+455.1 .
\end{gathered}
$$

And the value of $\varepsilon_{\mathrm{y}}$ in the empirical equation (5) is substituted in percent.

The relative specific load $\left(\eta_{\sigma}=p / \sigma_{s}\right)$ is possible to calculate based on the obtained results. The dimensionless quantity of $\eta_{\sigma}$ is independent of the properties of the workpiece material and is a function of the process type, i.e. function of the stress-strain state, which is characteristic of this process: $\eta_{\sigma}=f\left(\mu ; m_{0} ; \varepsilon_{y}\right)$, where $\mu$ is the contact friction coefficient. Bearing 
in mind when the workpiece has a ratio $m_{0}>1$ by the frictional forces are neglected $[1,5$, 29], then $\mu=0$; then $\eta_{\sigma}=f\left(m_{0} ; \varepsilon_{y}\right)$.

Assuming of $\delta \equiv \varepsilon$, used values obtained in equation (5) into equation (3) in relative units. Then, using the experimental results obtained from the equation (2) the graph $\eta_{\sigma}\left(m_{0} ; \varepsilon_{y}\right)$ was plotted (Fig. 6).

In the derivation of equation (5) the data of upset workpieces forming in the range of $\varepsilon_{y}=13 \ldots 53 \%$ was used, therefore the values of $\eta_{\sigma}$ for $\varepsilon_{y}<13 \%$ do not have a sufficient degree of reliability (in Fig. 3 they are represented by small dashed lines). The decrease in the relative specific load for workpieces with ratios $m_{0}=5.0 \ldots 6.0$ in the range of $\varepsilon_{y} \approx 20 \%$ to the value of $\eta_{\sigma}<1$ is associated with the growth of the deflection (load arm), and, correspondingly, the increase of the bending moment.

The conditional degree of deformation in 'upsetting-with-buckling' is technologically limited to a certain maximum value $\left(\varepsilon_{y, m a x}\right)$, the excess of which is corresponded with the danger of forming a "laps" or "folds" defects, therefore the graphs $\eta_{\sigma}\left(m_{0} ; \varepsilon_{y}\right)$ for $\varepsilon_{y}>\varepsilon_{y \text { max }}$ field are continued by a line-dotted lines (Fig. 6). Workpieces with ratio of $m_{0}=3.0$ do not buckled.

The load of the operation in the technologically permissible limits of the upsetting degree $0<\varepsilon_{y} \leq \varepsilon_{y, \max }$ is determined by the maximum of the force $\left(P_{m}\right)$ in upsetting stroke, to which corresponds a certain value of $\eta_{\sigma}=\eta_{\sigma . m}$ for a value $\varepsilon_{y}=\varepsilon_{y . m}$. In this case, for workpieces with ratios $m_{0}=3.5 \ldots 4.5$, the load increases throughout the entire course of upsetting stroke (Fig. 2-3), i.e. before $\varepsilon_{y, \max }$ and after this value, and consequently, the $\eta_{\sigma . m}$ value is realized at the $\varepsilon_{y, m}=\varepsilon_{y, \max }$.

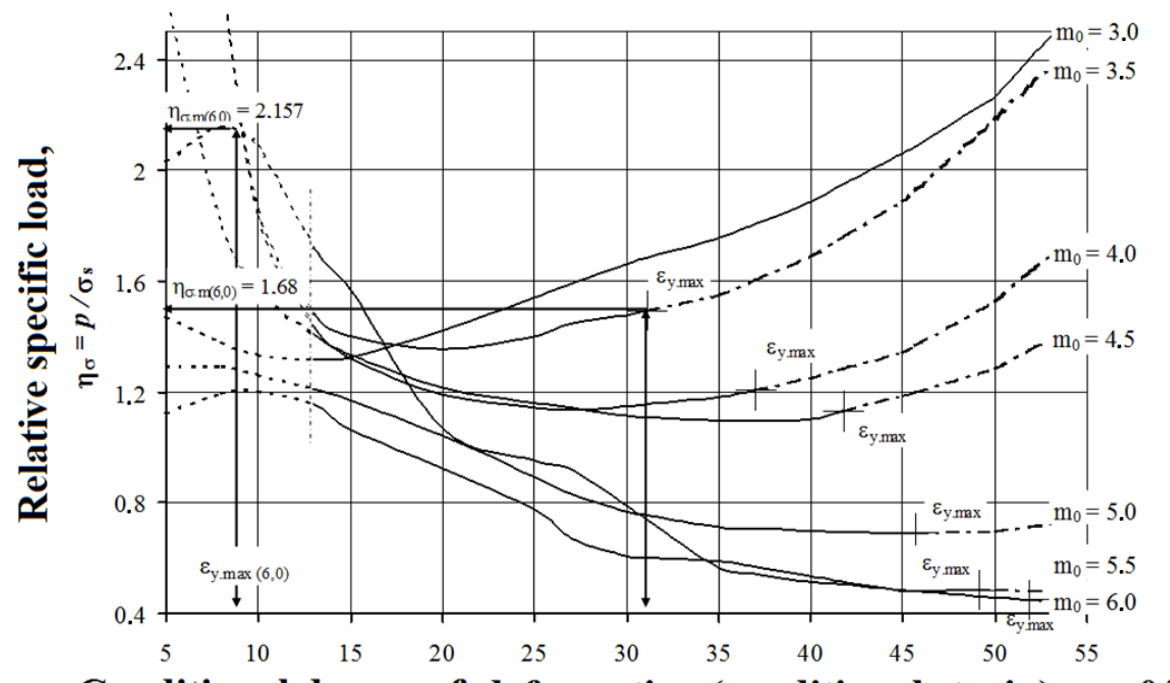

\section{Conditional degree of deformation (conditional strain), $\varepsilon_{y}, \%$}

Fig. 6. Relative specific load during upsetting with buckling

The method for finding $\eta_{\sigma . m}$ for billets with ratio of $m_{0}=3.5\left(\varepsilon_{y \cdot m(3,5)}=\varepsilon_{y \cdot \max (3,5)} \Rightarrow \eta_{\sigma \cdot m(3,5)}\right)$ is shown in Fig. 3 and Fig. 6. For workpieces with $m_{0}=4.5$ a characteristic region of $\varepsilon_{y}=17 \ldots 40 \%$ with a practically constant strain value was revealed, which is supposed to be due to the equal influence of the increasing bending moment and the increase of crosssectional area of workpieces. When the workpieces with $m_{0}=5.0 \ldots 6.0$ are deformed, the maximum load $\left(P_{m}\right)$ is realized at $\varepsilon_{y \cdot m}<\varepsilon_{y, \max }$, further sediment is accompanied by a decrease in load (Fig. 2 and Fig. 3). Then the $\eta_{\sigma . m}$ value can be determined from the graph 
(Fig. 6) at a known value of $\varepsilon_{y . m}$, which is found in advance in Fig. 3. The method of determining $\eta_{\sigma . m}$ for workpieces with the ratio of $m_{0}=6.0\left(p_{m(6,0)} \Rightarrow \varepsilon_{y . m(6,0)} \Rightarrow \eta_{\sigma . m(6,0)}\right)$ is shown in Fig. 3 and Fig. 6. The graph of the dependence $\eta_{\sigma . m}\left(m_{0}\right)$ is presented in Fig. 7.

Thus, the technological (maximum) load of the upsetting a workpiece of any material with buckling operation can be calculated as:

$$
P_{m}=k \cdot \eta_{\sigma . m} \cdot \sigma_{s} \cdot F_{0}
$$

where $k=1.25$ - reserve index;

$F_{0}$ - cross-section area of the workpiece;

$\sigma_{s}=\sigma_{s}(\delta)$ - the true stress, determined from the reference data [28] for $\delta \equiv \varepsilon$, after finding of $\delta$ by equation (5);

$\eta_{\sigma, m}$ - the relative specific load, determined by the curve in Fig. 7.

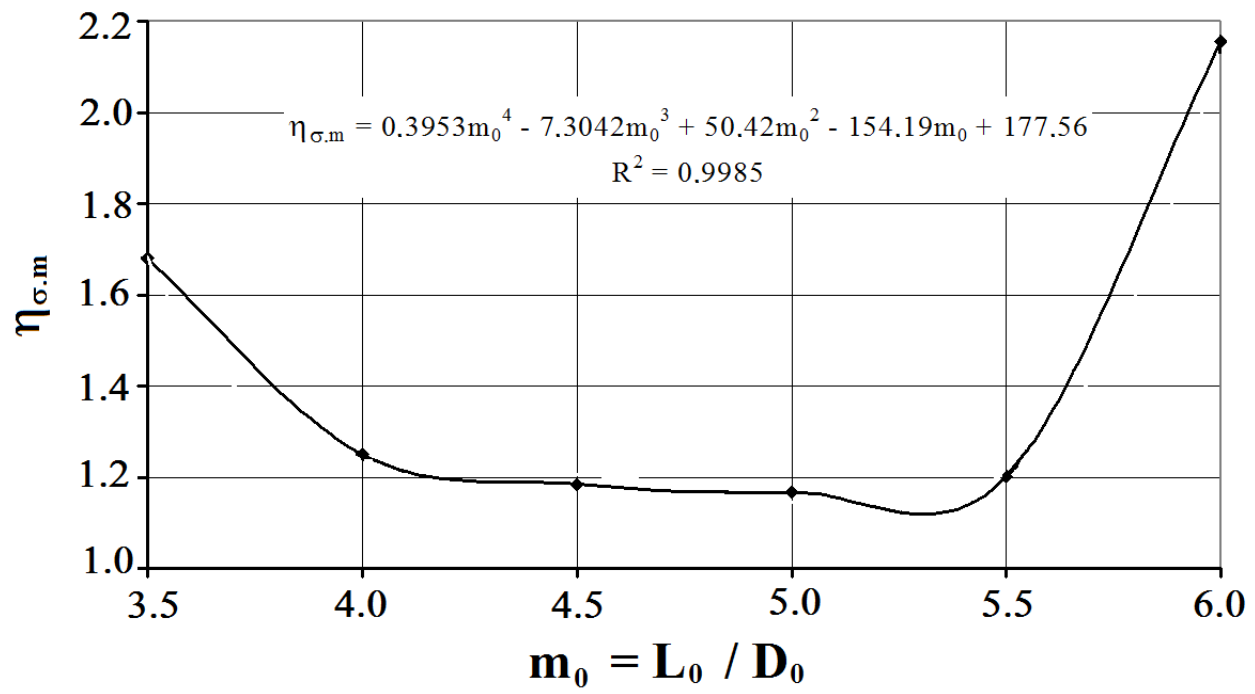

Fig. 7. The $\eta_{\sigma . m}\left(m_{0}\right)$ dependence

Example. Evaluate the possibility of sequential production of the preformed workpiece and closed die-forging of the "cardan fork" on a crank-press for hot bulk forming with a nominal force of $P_{p r}=10 \mathrm{MN}$. Material of workpiece is steel $40 \mathrm{X}$ grade $(\mathrm{C}=0.36 \ldots 0.44 \%$, $\mathrm{Si}=0.17 \ldots 0.37 \%, \quad \mathrm{Mn}=0.5 \ldots 0.8, \quad \mathrm{Ni}<0.3 \%, \quad \mathrm{~S}<0.035 \%, \quad \mathrm{P}<0.035 \%, \mathrm{Cr}=0.8 \ldots 1.1 \%$, $\mathrm{Cu}<0.3 \%, \mathrm{Fe} \approx 97 \%$ ), forging mass $-1.64 \mathrm{~kg}$, upsetting temperature $1100^{\circ} \mathrm{C}$. It is determined in advance: the dimensions of the workpiece are $L_{0}=216 \mathrm{~mm}, D_{0}=41 \mathrm{~mm}$ ( $m_{0}=5.27$ ratio); the required deformation degree at upsetting for preforming is $\varepsilon_{y}=36 \%$.

1) Calculating the axial shortening by equation (5) $\delta=14 \%$.

2) Determining $\sigma_{s}(\delta)$ of $40 \mathrm{X}$ grade steel with $\delta \equiv \varepsilon=14 \%, \dot{\varepsilon}=5 \mathrm{~s}^{-1}$, according to [28]: $\sigma_{s}=75 \mathrm{MPa}$.

3) According to the graph in Fig. 7 we find $\eta_{\sigma, m}=1.188$.

4) By the equation (6) we define $P_{m}=146969 \mathrm{~N}=0.147 \mathrm{MN}$.

5) The value of the forging force for horizontal (splash) forging in the final impression is calculated from the most unfavorable conditions (chilling of the workpiece, i.e., the temperature of the closed-die forging of $966^{\circ} \mathrm{C}$, the friction coefficient of $\mu=0.5$ ). Taking into account the influence of the strain rate and the $25 \%$ reserve, the calculated the force for closed die-forging: $P_{f}=7.35 \mathrm{MN}$. 
6) Comparing: $\left(P_{m}=0.147 \mathrm{MN}\right)<\left(P_{f}=7.35 \mathrm{MN}\right)<\left(P_{p r}=10 \mathrm{MN}\right)$.

At similar calculations, the preforming loads and the forces of the closed die-forging for forgings of a suitable nomenclature [30], the first one was always considerably less than the second one.

\section{Conclusions}

Experimental studies of the load of the 'upsetting-with-buckling' process of workpiece in the range of upsetting ratio of $m_{0}=L_{0} / D_{0}=3.0 \ldots 6.0$ are performed. Analysis of the experimental data allowed to develop an engineering method for calculating of process technological load for production of the preformed (shaped) workpieces by upsetting with buckling. This preparatory operation can be carried out unimpeded on the main die-forging equipment with successive or combined forging, because the load for preforming of workpiece is always substantially less than the final forming of the forging in the die impressions or final closed dies.

\section{References}

1. V.Kukhar, V.Artiukh, A.Butyrin, A.Prysiazhnyi. Advances in Intelligent Systems and Computing, vol 692. DOI: https://doi.org/10.1007/978-3-319-70987-1_22.

2. Taylan Altan, A.E.Tekkaya (2012). Sheet Metal Forming: Processes and Applications. ASM International, $\mathrm{OH}, 400 \mathrm{p}$.

3. Metal forming handbook / Schuler GmbH (1998). Springer, Berlin Heidelberg, 563 p., DOI: 10.1007/978-3-642-58857-0.

4. V.Kukhar, V.Burko, A.Prysiazhnyi, E.Balalayeva, M.Nahnibeda (2016). EastEuropean Journal of Enterprise Technology, 2016, 3/7(81), pp. 53-61. ISSN 17293774, DOI: 10.15587/1729-4061.2016.72063.

5. J.Singer, J.Arbocz, T.Weller (2007). Buckling Experiments, Basic Concepts, Columns, Beams and Plates: Vol. 1. Hoboken: Wiley, 2007.

6. J.Singer, J.Arbocz, T.Weller (1998). Buckling experiments: Experimental methods in buckling of thin-walled structures, Vol. 1, Chichester [u.a.]: Wiley, 1998.

7. J.G.Teng, J.M.Rotter (2006). Buckling of Thin Metal Shells, CRC Press, 2006, 520 p.

8. Nan Liu, He Yang, Heng Li, Siliang Yan (2016). Chinese Journal of Aeronautics, Vol. 29, Issue 1, 2016, Pages 1-14, ISSN 1000-9361, DOI: 10.1016/j.cja.2015.09.004.

9. V.Kukhar, E.Balalayeva, O.Nesterov (2017). MATEC Web of Conferences. (ICMTMTE), Vol. 129, 01041, 2017, DOI: 10.1051/matecconf/201712901041.

10. G.D.Gavrylenko (2007). Proceeding of the $13^{\text {th }}$ International conference on experimental mechanics, Alexandroupolis, Greece, July 1-6, 2007, pp. 783-784.

11. D.Quinn, A.Murphy, L.Cervi (2011). Proceedings of the Institution of Mechanical Engineers, Part G: Journal of Aerospace Engineering, 225(7), pp. 791-806. DOI: $10.1177 / 0954410011399035$.

12. J.Błachut, P.Smith (2007). Tabu search optimization of externally pressurized barrels and domes, Engineering Optimization, 39:8, pp.899-918, DOI: $10.1080 / 03052150701512604$.

13. B. Sidda Reddy, J. Suresh Kumar, C. Eswara Reddy, K. Vijaya Kumar Reddy. (2013). Journal of Composites, vol. 2013, Article ID 808764, 12 pages, 2013, DOI: $10.1155 / 2013 / 808764$. 
14. C.T.Tsai, O.W.Dillon, R.J. De Angelis (1988). Conference Record of the Twentieth IEEE Photovoltaic Specialists Conference, Las Vegas, NV, USA, 1988, Vol. 2., pp. 1545-1550, DOI: 10.1109/PVSC.1988.105968.

15. A.Dziubińska, A.Gontarz (2015). Limiting phenomena in a new forming process for two-rib plates, Metalurgija, 54(3), p. 555-558, http://hrcak.srce.hr/131621.

16. V.A.Grinkevich, V.V.Kukhar, K.K.Diamantopulo (2010). Kuznechnoshtampovochnoe proizvodstvo. Obrabotka materialov davleniem, 2010, No. 5, pp. 19 23. (in russian).

17. V.Kukhar, V.Artiukh, O.Serduik, E.Balalayeva (2016). Procedia Engineering, Vol. 165, 2016, pp. 1693-1704, DOI: 10.1016/j.proeng.2016.11.911.

18. V.V.Kukhar (2015) Metallurgical and Mining Industry, 2015, No. 6, pp. 122-132, http://www.metaljournal.com.ua/assets/Journal/MMI-6/016-Kukhar.pdf

19. M.Amino, M.Mizoguchi, Y.Terauchi, T.Maki (2015). Single Point "Dieless" Incremental Forming. In: Tekkaya A., Homberg W., Brosius A. (eds), 60 Excellent Inventions in Metal Forming. Springer Vieweg, Berlin, Heidelberg, DOI: 10.1007/978-3662-46312-3_24

20. Anna Kochan (2001). Dieless forming, Assembly Automation, Vol. 21, Issue: 4, pp. 321-323, DOI: 10.1108/01445150110407304.

21. M.D.Naughton, P.Tiernan (2009). An Experimental Approach to Continuous Dieless Wire Drawing (Variant A) Using ELI Ti-6Al-4V Alloy, ASME. J. Eng. Mater. Technol. 2009; 131(2):021005-021005-10, DOI: 10.1115/1.3078304.

22. Y.M.Hwang, T.Y.Kuo (2013). The International Journal of Advanced Manufacturing Technology, Vol. 68, Issue 5-8, pp. 1311-1316, DOI: 10.1007/s00170-013-4922-0.

23. P.Kustra, A.Milenin, B.Płonka, T.Furushima (2016) Journal of Materials Engineering and Performance, Volume 25, Issue 6, pp. 2528-2535, DOI: 10.1007/s11665-0162090-8.

24. S-S.Huang, I.Burgess, Z.Huang, R.Plank (2011). Proceedings of the Institution of Civil Engineers: Engineering and Computational Mechanics, Vol. 164 (2). pp. 103-119. ISSN 1755-0777, DOI: 10.1680/eacm.2011.164.2.103.

25. J.W.Hutchinson (1974). Plastic buckling, Advanced in Applied Mechanics, Vol. 14, Academic press, inc., New York, pp. 67-144.

26. Y.V.Narayana, J.B.Gunda, R.R.Pinninti, M.Ravvala (2015). World Journal of Engineering and Technology, Issue 3, pp. 185-194, DOI: 10.4236/wjet.2015.34019.

27. G.G.Shlomchack, I.Mamuzič, F.Vodopivec (1994). Rheologically similarity of metals and alloys, J. of Materials Processing Technology, Amsterdam-New-York: Elsevier, 1994, Vol. 40, № 3-4, pp. 315-325.

28. P.I.Poluhin, G.Ja.Gun, A.M.Galkin (1983). Soprotivlenie plasticheskoj deformacii metallov i splavov. Spravochnik [Resistance to plastic deformation of metals and alloys. Reference book], Moscow, Metallurgija, 1983, 352 p. (in russian).

29. V.I.Kaplanov, A.G.Prisyazhnyi (2008). Simulation of contact friction in the hot rolling of steel sheet, Steel in Translation, Vol. 38, No. 9, pp. 714-718, DOI: 10.3103/S0967091208090040.

30. A.S.Semenov, S.G.Semenov, B.E.Melnikov, V.S.Tikhonov. Magazine of Civil Engineering. 2017. No. 6. Pp. 78-101. doi: 10.18720/MCE.74.8 